\title{
Long-term outcome of everolimus treatment in transplant patients
}

This article was published in the following Dove Press journal:

Transplant Research and Risk Management

12 May 2011

Number of times this article has been viewed

\section{Maurizio Salvadori \\ Elisabetta Bertoni \\ Renal Unit, Careggi University Hospital, Florence, Italy}

Correspondence: Maurizio Salvadori Renal Unit, Careggi University Hospital, viale Pieraccini I8, 50I39 Florence, Italy Tel +390557949269

Fax +39055 435878

Email maurizio.salvadori@unifi.it
Abstract: The authors review the use of everolimus in long-term studies both in renal and heart transplantation. The pharmacokinetic and pharmacodynamic differences between everolimus and its parent drug, sirolimus are discussed. The improved pharmacokinetic, in particular the improved bioavailability, the reduced half-time and the reduced binding to plasma protein makes everolimus the first choice among the proliferation signal inhibitors. Everolimus is given in almost all studies in association with cyclosporine, but fixed doses of this drug can cause nephrotoxicity. The first studies used everolimus and CsA in fixed doses, but later studies with reduced CsA doses revealed which revealed improved outcomes. Finally, therapeutic drug monitoring became the better choice for both drugs. Recently very high everolimus exposure allowed the use of very low CsA exposure with improvement of the worse side effects linked to the CsA standard dose. The Zeus study revealed a complete and safe CsA withdrawal, thanks to everolimus and mycophenolic acid. In heart transplantation, everolimus resulted in improved outcomes with respect to antiproliferative drugs such as mycophenolic acid and azathioprine. Along with antirejection properties, everolimus provided evidence for antiproliferative effects on several cells. This resulted in fewer viral infections (mainly CMV), anti-atherosclerotic properties (mainly important in heart transplantation, and antineoplastic effect. The latter activity resulted in lower cancer incidence in transplant patients treated by everolimus. An important piece of evidence for this activity is documented by the use of everolimus in the treatment of some cancers, including renal cancer, neuroendocrine cancers and hepatocellular cancers, also outside the field of transplantation.

Keywords: everolimus, renal transplantation, heart transplantation, CNI minimization, CNI withdrawal

\section{Introduction}

The evolution of immunosuppressive therapies since the 1980s has led to lower rejection rates and improved recipient and short-term allograft survival, primarily because of the use of calcineurin inhibitors, which are still the cornerstone of the maintenance phase of immunosuppression. The aim of this review is to highlight the role of everolimus, based on long-term studies, in the modern era of immunosuppression.

In 2006, the Scientific Registry of Transplant Recipients reported that 93\% of recipients leaving hospital with a kidney transplant were receiving a calcineurin inhibitor. ${ }^{1}$ By the beginning of the 2000 s, 1-year allograft survival rates approached $90 \%$, whereas acute rejection rates were below 20\%. On the other hand, long-term calcineurin inhibitor-based immunosuppression is associated with nephrotoxicity (cyclosporine, tacrolimus) and other adverse effects, including hypertension (cyclosporine), hyperlipidemia (cyclosporine), and diabetes (tacrolimus). 
As a consequence, long-term improvement in allograft survival did not improve, as expected.

Studies conducted in the early to mid 1990s suggested that decreasing early acute rejection rates would lead to improvement in long-term allograft survival. Notwithstanding, between 1988 and 1995, there was a slight increase in transplanted kidney half-life as calculated from Kaplan-Meier curves., ${ }^{2,3}$ The observed limited improvement in half-lives highlights the concern that calcineurin inhibitor nephrotoxicity might interfere with a significant improvement in long-term survival.

Few issues in immunosuppression are as controversial as the use of calcineurin inhibitors. Although the short-term benefits of calcineurin inhibitors are unquestionable, their effects on long-term outcomes are debated. ${ }^{4}$ Minimization, withdrawal, or elimination of calcineurin inhibitors could minimize the toxicities attributed to these agents, in particular nephrotoxicity. The availability of mycophenolic acid and proliferation signal inhibitors could allow calcineurin inhibitor-sparing regimens designed to decrease exposure to these agents. Three calcineurin inhibitorsparing strategies have been studied, ie, calcineurin inhibitor withdrawal or elimination, calcineurin inhibitor minimization, and calcineurin inhibitor avoidance. Attempts to withdraw cyclosporine with the use of mycophenolic acid did not result in improved outcomes. Indeed the cyclosporine withdrawal study group ${ }^{5}$ was stopped for an excess of rejection. Better results were obtained by the CAESAR (Cyclosporine sparing with mycophenolate mofetil, daclizumab and corticosteroids in renal allograft recipients) study, ${ }^{6}$ even if cyclosporine withdrawal was associated with a higher rejection rate.

Besides mycophenolate mofetil, potential alternatives to the traditional calcineurin inhibitor-based regimens are calcineurin inhibitor-sparing regimens with the use of proliferation signal inhibitors. So far, sirolimus and everolimus are the two available compounds of this class. In addition to lacking intrinsic nephrotoxicity and exhibiting sufficient immunosuppressant activity, some of the nonimmunosuppressant effects of these compounds may actually turn out to be clinically useful. For example, their strong antigrowth effect is currently being studied in patients with renal cell cancer in their native kidneys. ${ }^{7}$ Furthermore, recent experimental data suggest that mammalian target of rapamycin (mTOR-I) inhibitors may cause fewer glucose utilization problems. ${ }^{8}$

\section{Pharmacokinetics and pharmacodynamics}

Sirolimus, first discovered in soil samples from Easter Island in 1964, is a macrocyclic lactone antibacterial isolated by the fungus Streptomyces hygroscopius, and has been found to have potent immunosuppressive properties. ${ }^{9}$ Everolimus (RAD, [40-O-[2-hydroxyethyl]-rapamycin]) is a novel macrolide immunosuppressant that has been developed for use in combination with cyclosporine for prophylaxis of acute rejection and prevention of chronic rejection in patients receiving kidney, heart, lung, and liver transplants.

Everolimus is a new, orally active proliferation signal (mTOR) inhibitor that blocks late cell cycle events in response to growth factors in the cellular response to alloantigens. Everolimus, which has greater polarity and is more hydrophilic, was developed to improve the pharmacokinetic and pharmacodynamic properties of sirolimus, especially oral bioavailability. ${ }^{10}$ The chemical structures of everolimus and sirolimus differ by the presence of a 2-hydroxyethyl group at position 40 (Figure 1).

Despite the similarities in chemical structure, there are important pharmacokinetic and pharmacodynamic differences between everolimus and sirolimus. The higher oral bioavailability ( $20 \%$ vs $14 \%$ ), and the lower plasma protein binding (74\% vs 92\%) allow everolimus to have a shorter time to steady state (4 days vs 5-7 days). As a consequence, sirolimus needs an initial oral load that may increase its negative side effects. The shorter half-life and twice-daily dosing for everolimus facilitate dose adjustment to achieve target levels. As a consequence of its increased oral bioavailability, everolimus is twice as potent in vivo as sirolimus on oral dose comparison, implying improved gut absorption (Tables 1 and 2). ${ }^{11}$

Only one of the seven major metabolites of sirolimus and two of the nine main metabolites of everolimus have any immunosuppressive potency. However, these are negligible contributors to the biological effect of the drugs. Both sirolimus and everolimus are substrates for hepatic and intestinal cytochrome P450 (CYP) 3A4 enzymes, as well as for $\mathrm{P}$ glycoprotein. ${ }^{11}$ The difference in potency between sirolimus and everolimus may explain the different target trough blood levels, which are $3-8 \mathrm{ng} / \mathrm{mL}$ for everolimus and $4-12 \mathrm{ng} / \mathrm{mL}$ for sirolimus.

Everolimus is absorbed rapidly, with peak blood concentrations $\left(\mathrm{C}_{\max }\right)$ being reached 1-2 hours after an oral dose. Steady state is generally achieved by day $4 .^{12}$ Absorption kinetics were dose-proportional in renal transplant recipients after oral doses of $1.5 \mathrm{mg} /$ day or $3 \mathrm{mg} /$ day in combination with cyclosporine microemulsion and corticosteroids in a 6-month study. ${ }^{13}$ Mean minimum trough blood everolimus concentrations $\left(\mathrm{C}_{\min }\right)$ should be maintained above the therapeutic threshold of $3 \mathrm{ng} / \mathrm{mL}$. 


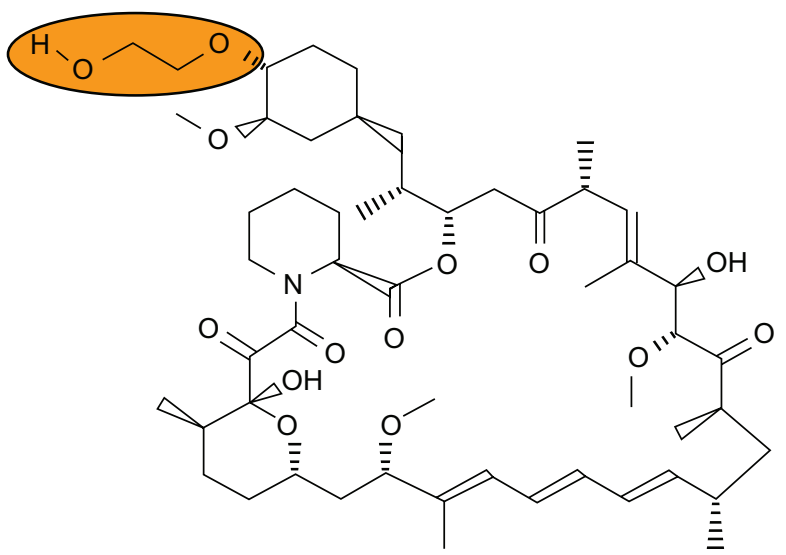

Everolimus

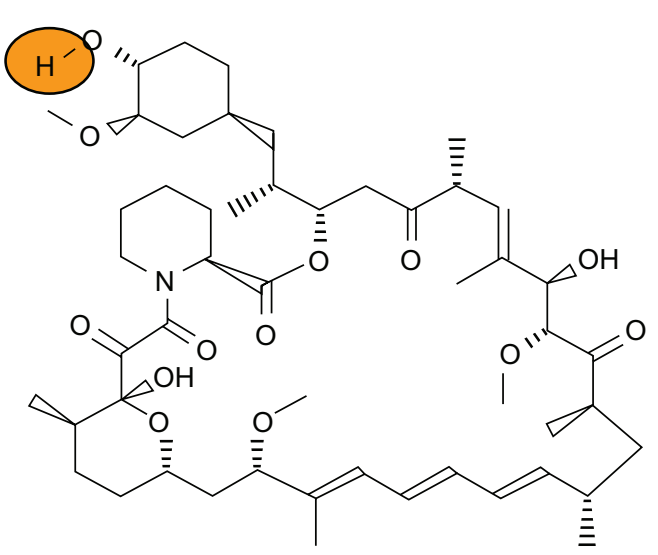

Sirolimus

Figure I Chemical structures of everolimus and sirolimus.

Moreover, mean $\mathrm{C}_{\text {min }}$ values were also maintained above the therapeutic threshold in cardiac transplant recipients receiving everolimus $1.5 \mathrm{mg}$ /day or $3 \mathrm{mg} /$ day over 6 months. ${ }^{14}$

Dose-proportional kinetics, as shown by the area under the blood-concentration time curve (AUC), were also reported after a single dose of everolimus (administered alone),${ }^{15}$ and after multiple doses of up to $5 \mathrm{mg} /$ day. ${ }^{16}$ Systemic exposure (AUC and $\mathrm{C}_{\max }$ ) was also dose-proportional in cardiac transplant recipients. ${ }^{14}$ In renal transplant patients, inter- and intraindividual variability for AUC was $31 \%$ and $27 \%$, respectively, suggesting the need for therapeutic drug monitoring. ${ }^{13}$

The bioavailability of everolimus is affected by food, as shown by delays in time to reach peak concentration $\left(\mathrm{t}_{\max }\right)$ of up to a median 1.75 hours and reductions in $\mathrm{C}_{\max }$ by up to a mean of $60 \%$, associated with high-fat meals with respect to the fasting state, in studies including 24 healthy volunteers and six renal transplant recipients. ${ }^{17}$ Although systemic exposure to everolimus was reduced to a more modest extent (by 16\% in volunteers and $21 \%$ in patients), consistent administration of the drug either with or without food is recommended to minimize variability in patient exposure. ${ }^{17}$ Although tissue distribution in humans has not been determined, the highest tissue concentrations in monkeys have been measured in

Table I Pharmacokinetic characteristics of Everolimus and Sirolimus

\begin{tabular}{lll}
\hline & Everolimus & Sirolimus \\
\hline Oral bioavailability & $20 \%$ & $14 \%$ \\
Time to reach peak plasma concentration & $\mathrm{I}-2$ hours & $\mathrm{I}-2$ hours \\
Elimination half-life & 28 hours & 62 hours \\
Dosing interval & Twice daily & Once daily \\
Time to steady state & 4 days & $5-7$ days \\
Plasma protein binding & $74 \%$ & $92 \%$ \\
\hline
\end{tabular}

the gall bladder, pancreas, transplanted lung, cerebellum, kidneys, and spleen. ${ }^{18}$

Like sirolimus, everolimus blocks growth factor-stimulated cell proliferation (of both hemopoietic and nonhemopoietic cells) by forming a complex with the intracellular immunophyllin, FK506 (tacrolimus)-binding protein 12 (FKBP12). This complex binds to FKB12-rapamycin-associated protein (FRAP, also known as mTOR) and blocks its activity, which includes the phosphorylation of p70 S6 kinase and subsequent protein synthesis. ${ }^{19}$ This arrests the cell cycle at G1 phase, and prevents progression to $\mathrm{S}$ phase. The affinity of everolimus for FKBP12 is lower than that of sirolimus.

The mechanism of action of everolimus differs from that of the calcineurin inhibitors, which bind to the intracellular protein, cyclophyllin, and thereby inhibit calcium-dependent T lymphocyte activation by interfering with the ability of the cell to transcript interleukin-2 (IL-2). It also differs from that of mycophenolate mofetil, which is a noncompetitive, selective, and reversible inhibitor of inosine monophosphate dehydrogenase, an important enzyme in the synthesis of guanosine nucleotides in $\mathrm{T}$ and $\mathrm{B}$ lymphocytes. The main cells targeted by everolimus, as well as by sirolimus, are

Table 2 Pharmacokinetic characteristics

- Everolimus is twice as potent in vivo as sirolimus on a oral dose comparison, implying improved gut absorption

- Passive permeability through the gut wall; everolimus twice that of sirolimus

- Passive first-pass extraction of sirolimus greater than everolimus; increased sirolimus metabolism by gut (cytochrome P450 3A4), and more efflux back into the gut lumen

- Cytochrome P450 3A4 polymorphism - increased sirolimus doses to achieve therapeutic $\mathrm{CO}$ 
Table 3 Cells targeted by everolimus

\begin{tabular}{lll}
\hline Cell type & Growth factor & IC $_{50}(\mathbf{n M})$ \\
\hline T cells & IL-2 & $2.0 \pm 0.8$ \\
T cells & IL-I5 & $2.0 \pm 1.6$ \\
B cells & IL-6 & $2.5 \pm 0.7$ \\
Smooth muscle cells & FCS & $1.9 \pm 0.8$ \\
HaCaT (keratocyte cells) & FCS & $0.2 \pm 0.1$ \\
Synovial cells & FCS & $0.1 \pm 3.0$ \\
\hline
\end{tabular}

Abbreviations: FCS, fetal calf serum; IL, interleukin.

shown in Table 3. Besides targeting cells of the immune system, proliferation signal inhibitors, including everolimus and sirolimus, have an important antiproliferative effect on other cells, including cancer cells, hence their antineoplastic action. Indeed, these drugs, besides impairing cancer cells by increasing E cadherin, decrease the cyclin pathway and the cell cycle, by decreasing IL-10 and the Jak/STAT system. They also have an important role as antineoplastic agents via mTOR inhibition and consequent inhibition of cell proliferation, including endothelial cells and tumor cells (Figure 2).

\section{Use in renal transplantation}

Everolimus and cyclosporine displayed synergistic immunosuppressive activity when used in combination in vitro and in preclinical models, predicting that they could be used together at lower doses in humans. The immunosuppressive ability of everolimus has been clearly documented in preclinical studies, showing efficacy in an in vitro model of mixed lymphocyte culture, ${ }^{20}$ efficacy in heart and kidney allotransplants in mouse and rat models, ${ }^{20,21}$ and efficacy in kidney and lung transplantation in monkeys. ${ }^{22}$ Overall, the preclinical studies showed:

- The potential of everolimus as an immunosuppressant in rodent and nonhuman primate models of solid organ transplantation

- Everolimus was well tolerated after single oral administration in acute toxicity studies

- In repeated-dose toxicity studies, effects secondary to immunosuppression were evident at higher dosages in all species

- Evaluation of combination studies of everolimus with other immunosuppressive compounds, such as cyclosporine, revealed toxicities often notably exacerbated compared with those when the compounds were administered alone.

Given the efficacy and the tolerability documented by preclinical models, trials in humans were started, taking in account the interferences between everolimus and cyclosporine. Trials in renal transplantation included a Phase II study evaluating everolimus in combination with either full-dose or reduced-dose cyclosporine and corticosteroids (Study 156), ${ }^{23}$ two Phase III trials comparing everolimus vs mycophenolate mofetil when combined with full-dose cyclosporine and corticosteroids (Study 201 and Study 251), ${ }^{24-26}$ and two trials evaluating concentration-controlled everolimus in combination with reduced-dose cyclosporine and corticosteroids (Study 2306 and Study 2307). ${ }^{27}$ More recently, trials in renal transplantation attempting to minimize or withdrawal cyclosporine have been successfully performed. ${ }^{28,29}$

\section{Long-term and short-term efficacy}

Study 251 and Study 201 were 3-year, randomized, multicenter, parallel-group studies that investigated the efficacy and safety of everolimus $1.5 \mathrm{mg}$ /day or $3 \mathrm{mg} /$ day, vs mycophenolate mofetil $2 \mathrm{~g} /$ day, as part of a triple immunosuppressive regimen (concomitant cyclosporine and prednisone) in de novo renal transplant recipients. The studies included a 1-year, double-blind, double-dummy initial phase, followed by an open-label renal amendment phase during the next 2 years, and were powered to demonstrate equivalence between everolimus and mycophenolate mofetil. A total of 583 patients were enrolled into Study 251 from centers in North and South America, and 588 patients were enrolled for Study 201 worldwide (Australia, Europe, and South America).

The primary objective of both studies was to compare the efficacy of the two oral doses of everolimus $(0.75 \mathrm{mg}$ or $1.5 \mathrm{mg}$ twice daily vs mycophenolate mofetil $1 \mathrm{~g}$ twice daily), as measured by the incidence of efficacy failure (ie, biopsyproven acute rejection, graft loss, death, or loss to follow-up) during the first 6 months of treatment, and the incidence of graft loss, death, or loss to follow-up during the first 12 months of treatment. The studies also considered efficacy at months 24 and 36 . The secondary efficacy variables were incidence of biopsy-proven acute rejection episodes, graft loss, death, biopsy-proven acute rejection episodes requiring antibody treatment, and chronic rejection episodes. Additional endpoints in Study 201 included prevention of chronic allograft rejection, safety, pharmacokinetics of everolimus, and healthrelated quality of life.

The results of both studies after 12 months, as well as after 36 months, suggested that everolimus and mycophenolate mofetil were comparable in the prevention of acute rejection in renal transplant patients, and no differences were observed in efficacy between the everolimus $1.5 \mathrm{mg} /$ day and $3 \mathrm{mg} /$ day groups. Most cases of biopsy-proven acute rejection were mild or moderate in severity (Banff Grade I or II). 


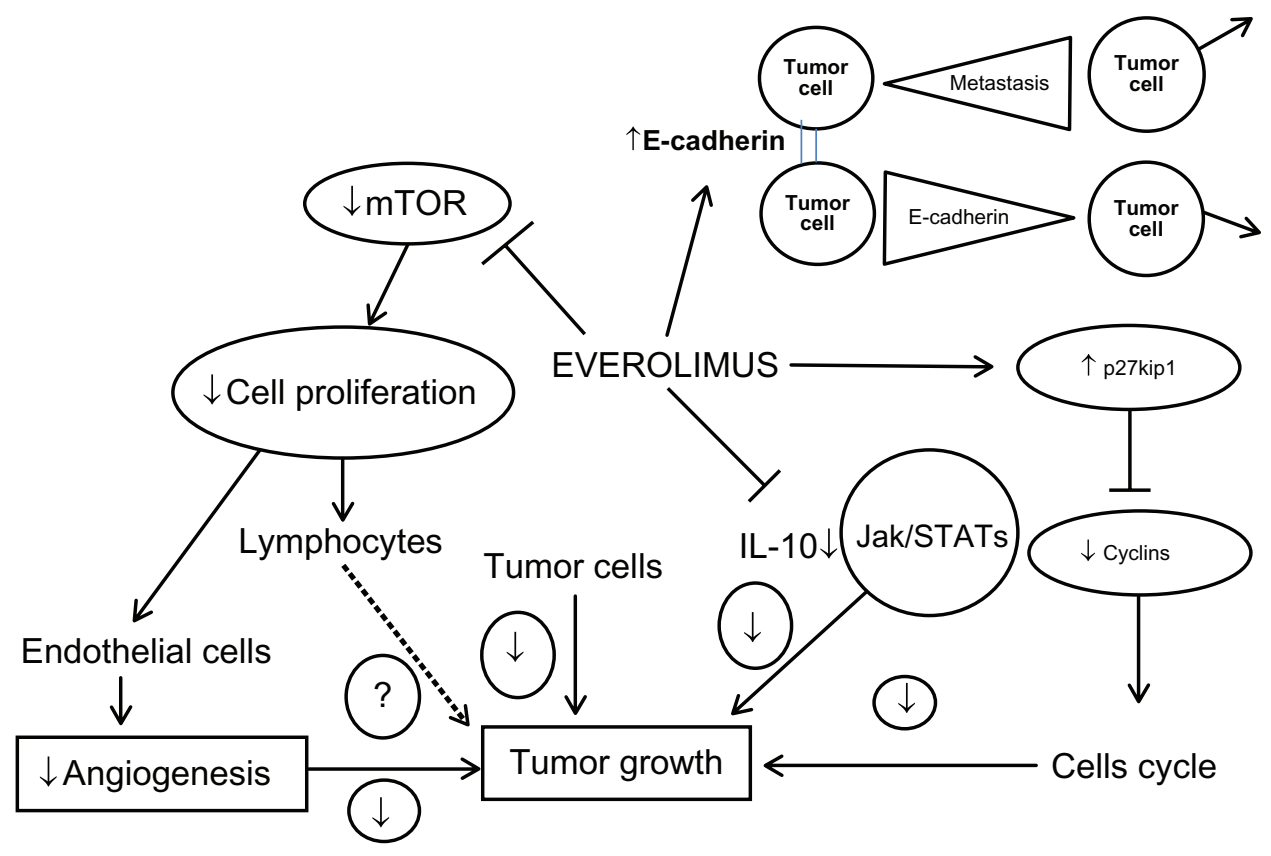

Figure 2 Antineoplastic pathways for everolimus.

The incidence of antibody-treated acute rejection was similar in the everolimus $1.5 \mathrm{mg}$ and $3 \mathrm{mg}$ groups (10\% and $14 \%$, respectively), but was higher in the mycophenolate mofetil group (18\%), with a significant difference between the everolimus $1.5 \mathrm{mg}$ and mycophenolate mofetil groups. Similarly, the incidence of graft loss or death was comparable between the two groups. Table 4 shows the main efficacy data at month 36 for Study 251.

Cox regression analysis indicates that patients with trough levels $<3 \mathrm{ng} / \mathrm{mL}$ had a significantly increased risk of having biopsy-proven acute rejections than those with everolimus trough levels within the $3-8 \mathrm{ng} / \mathrm{mL}$ range (relative risk increased 3.4 fold; $P<0.0001) .{ }^{30}$ As a consequence, during the open-label phase (months 12-36), a renal amendment was

Table 4 Efficacy of everolimus and mycophenolate mofetil at 36 months from Study 25।

\begin{tabular}{llll}
\hline & $\begin{array}{l}\text { Everolimus } \\
\mathbf{I . 5} \mathbf{~ m g / d a y} \\
(\mathbf{n}=1 \mathbf{1 9 3})\end{array}$ & $\begin{array}{l}\text { Everolimus } \\
\mathbf{3 . 0} \mathbf{~ m g / d a y} \\
(\mathbf{n}=194)\end{array}$ & $\begin{array}{l}\text { MMF } \\
(\mathbf{n}=196)\end{array}$ \\
\hline $\begin{array}{l}\text { Primary efficacy } \\
\text { failure }\end{array}$ & $65(33.7 \%)$ & $66(34 \%)$ & $62(31.1 \%)$ \\
BPAR & $49(25.4 \%)$ & $50(25.8 \%)$ & $52(26.5 \%)$ \\
Graft loss/death & $31(16.1 \%)$ & $27(13.9 \%)$ & $20(10.2 \%)$ \\
Graft loss & $23(11.9 \%)$ & $15(7.7 \%)$ & $14(7.1 \%)$ \\
$\begin{array}{l}\text { Death } \\
\text { Lost to follow-up }\end{array}$ & $2(2(6.2 \%)$ & $13(6.7 \%)$ & $10(5.1 \%)$ \\
Antibody-treated & $10 \%$ & $1(0.5 \%)$ & $1(0.5 \%)$ \\
acute rejection & & $14 \%$ & $18 \%$ \\
\hline
\end{tabular}

Abbreviations: BPAR, biopsy-proven acute rejection; MMF, mycophenolate mofetil. applied so that doses of everolimus were adjusted to provide trough levels $\geq 3 \mathrm{ng} / \mathrm{mL}$, and doses of cyclosporine were adjusted to provide a trough level of $50-75 \mathrm{ng} / \mathrm{mL}$. The main drawback of both studies was a higher serum creatinine level in patients receiving everolimus vs mycophenolate mofetil. Figure 3 shows 12-month data from Study 201.

In conclusion, everolimus and mycophenolate mofetil with full-dose cyclosporine showed similar efficacy. These studies had the power to demonstrate the efficacy of everolimus (trough levels $>3 \mathrm{ng} / \mathrm{mL}$ ) in association with cyclosporine in renal transplant recipients. The main weakness of these studies was the higher serum creatinine level in patients receiving everolimus than that in patients receiving mycophenolate mofetil, indicating potential nephrotoxicity with full-dose cyclosporine (Figure 4). These data indicate that cyclosporine reduction should be done gradually in the late posttransplant period in order to optimize benefit/risk.

Study B156 was a Phase II, 3-year, multicenter, randomized, open-label, parallel-group, dose-finding study of everolimus in de novo transplant recipients. ${ }^{23}$ All patients enrolled in the study received everolimus $3 \mathrm{mg} /$ day (fixed dose) plus methylprednisone (standard dosing, started immediately prior to transplantation) and basiliximab as induction therapy (20 mg on days 0 and 4). After transplantation, patients were randomized to either full-dose (trough level $125-250 \mathrm{ng} / \mathrm{mL}$ from 3-36 months) or reduced-dose cyclosporine (trough blood levels 50-100 ng/mL from 3-36 months). The study was also subject to the renal protocol amendment, reducing 


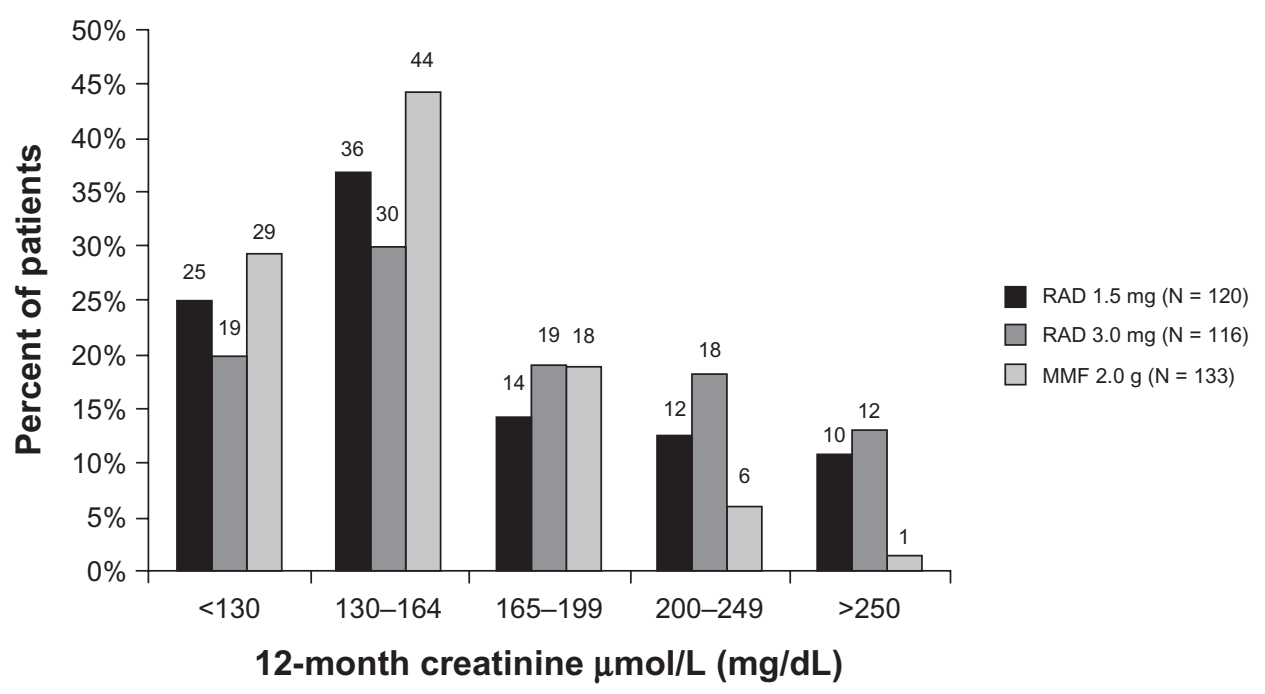

Figure 3 Serum creatinine values after 12 months on treatment (Study B20I).

cyclosporine exposure after 12 months in both study groups. The strength of the B156 study was that it showed in de novo renal transplant recipients, that the regimen of everolimus plus reduced-dose cyclosporine is well tolerated, with low efficacy failure and better renal function in comparison with everolimus plus full-dose cyclosporine (Figure 5).

In light of the findings from these studies, two prospective, multicenter, randomized studies were set up to evaluate the efficacy and safety of two doses of everolimus $(1.5 \mathrm{mg} /$ day vs $3 \mathrm{mg} /$ day) in combination with low-exposure cyclosporine and corticosteroids in de novo renal transplant recipients. The A2306 study $(\mathrm{n}=237)$ had no induction therapy, and in the A2307 study $(n=256)$ basiliximab was administered. An open-label design was adopted because therapeutic drug monitoring required the investigators to adjust the dose of everolimus. In these prospective, randomized studies

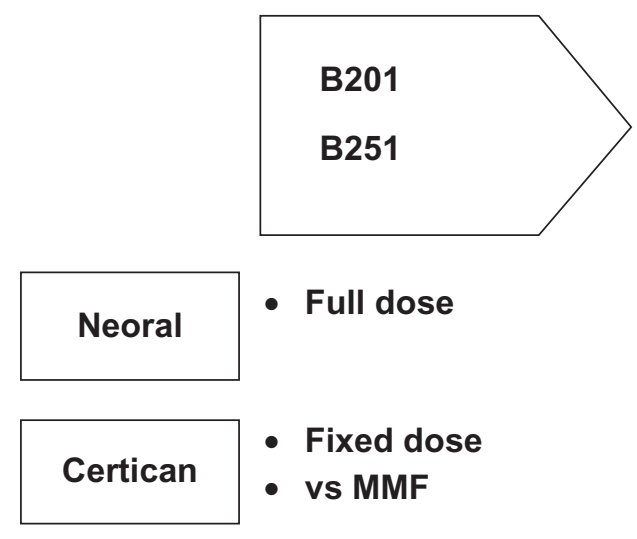

\section{Creatinine}

Figure 4 I) Optimizing the use of everolimus $\left(\right.$ Certican $\left.^{\circledR}\right)$ in renal transplantation.
(A2306 and A2307), the primary endpoint was renal function at 6 months, and the secondary endpoints included incidence of efficacy failure (first occurrence of either biopsy-proven acute rejection, graft loss, death, or loss to follow-up). ${ }^{27}$ Everolimus dosing was adjusted to maintain a trough level $\geq 3 \mathrm{ng} / \mathrm{mL}$. For the first time in the everolimus studies, the concept of therapeutic dose monitoring was introduced. The overall design of the studies is shown in Figure 6.

Median creatinine levels at 6 and 12 months were less than $135 \mu \mathrm{mol}$ in both groups and in both studies. These results for renal function were comparable with those observed with mycophenolate mofetil arm in the B251 study and were better than the B201 results. ${ }^{31}$ Comparing the renal function evaluated by creatinine clearance in the different arms of B156 and A2307, we obtained the results showed in Figure 7.

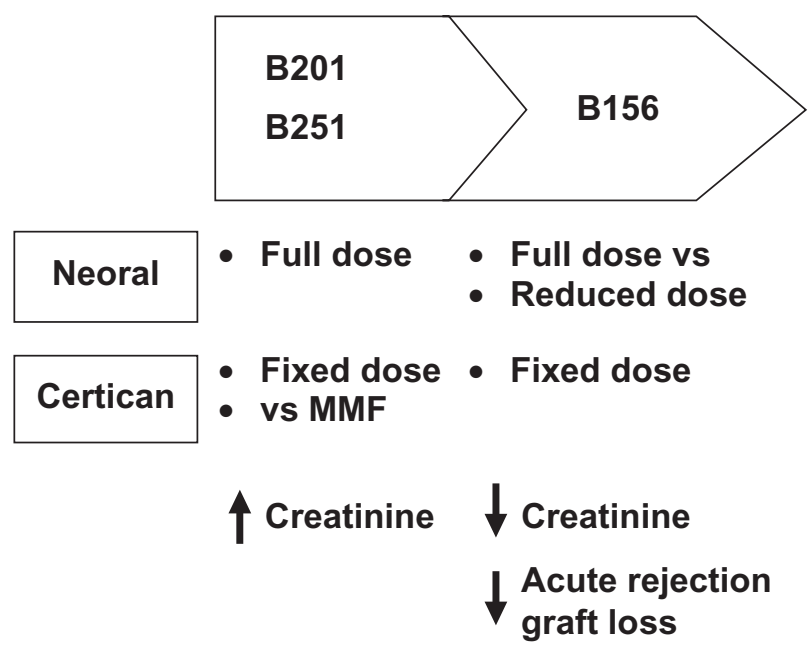

Figure 5 II) Optimizing the use of everolimus $\left(\right.$ Certican $\left.^{\circledR}\right)$ in renal transplantation. 


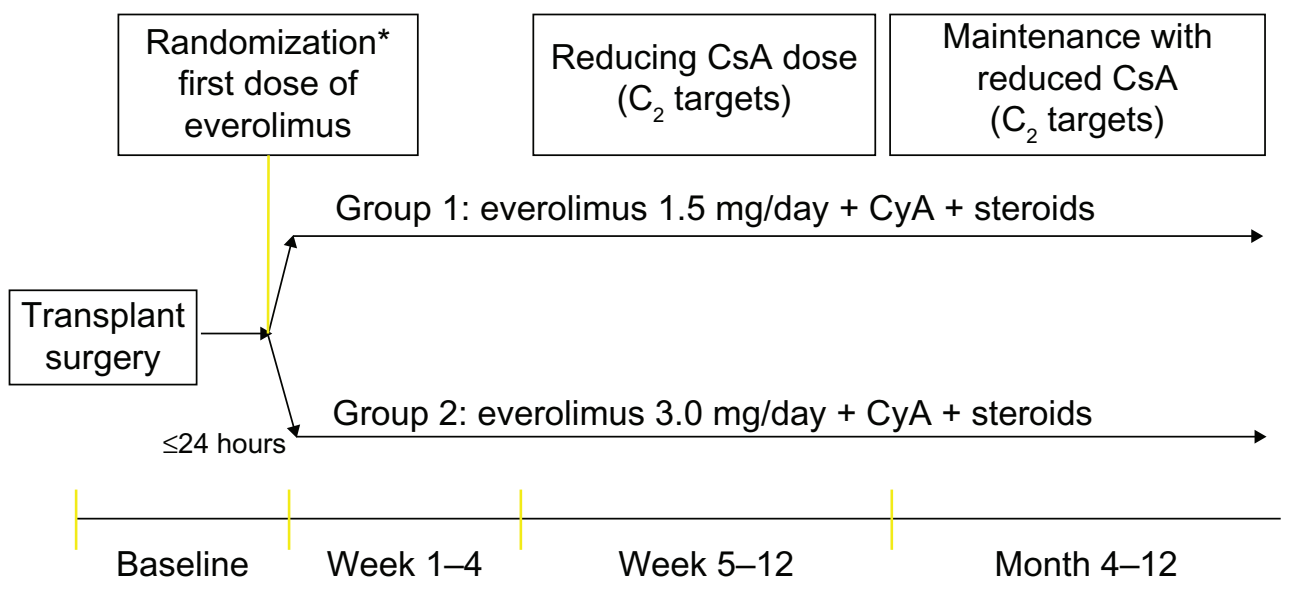

Figure 6 Everolimus and reduced-exposure calcineurin inhibitor (Study 2306/2307).

Note: *Black patients are enrolled to receive everolimus $3.0 \mathrm{mg} /$ day'. Basiliximab (Days 0 and 4) also administered in Study 2307.

The incidences of efficacy failure and biopsy-proven acute rejection were comparable with those observed in the B251 and B201 studies. However, biopsy-proven acute rejection occurred more frequently with everolimus $1.5 \mathrm{mg} /$ day in study A2306 (25\%) than in study A2307 (13.7\%), suggesting that anti-IL-2 receptor induction therapy is probably beneficial for reducing the risk of early biopsy-proven acute rejection when used with a lower dose of everolimus. ${ }^{32}$ The strength of these studies was the documentation that concentration-controlled everolimus in combination with low-exposure cyclosporine results in effective protection against rejection with good renal function (Figure 8). Later on, two further studies compared a high-dose everolimus therapy, very low-dose cyclosporine, and steroid combination with an enteric-coated mycophenolic acid, standard-dose cyclosporine, and steroid combination.

In the large open-label A2309 study, ${ }^{33} 833$ de novo renal transplant patients were randomized to receive everolimus

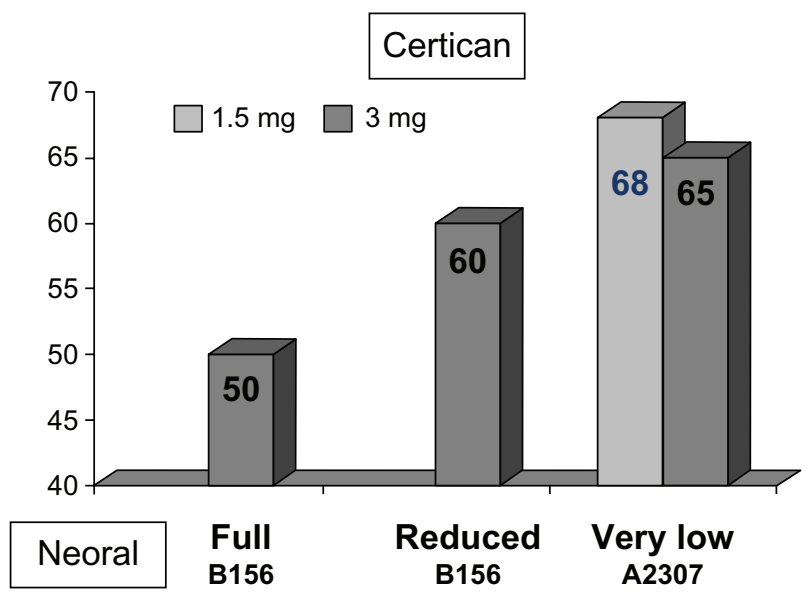

Figure 7 Renal function: 6-month creatinine clearance (Study A2307 vs $\mathrm{C}_{0}$ /full-dose and reduced-dose cyclosporine.
$1.5 \mathrm{mg} /$ day or $3 \mathrm{mg} /$ day (target trough levels $3-8 \mathrm{ng} / \mathrm{mL}$ and $6-12 \mathrm{ng} / \mathrm{mL}$, respectively) with reduced-exposure cyclosporine or mycophenolic acid $1440 \mathrm{mg}$ /day plus standard-exposure cyclosporine. All patients received basiliximab and corticosteroids. The primary efficacy endpoint was efficacy failure, defined as the composite of biopsyproven acute rejection, graft loss, death, or loss to follow-up at 12 months. The main safety endpoint was renal function at month 12. Efficacy failure rates at month 12 were noninferior in the everolimus $1.5 \mathrm{mg} /$ day (25.3\%) and $3 \mathrm{mg} /$ day (21.9\%) vs mycophenolic acid (24.2\%) groups. Mean estimated glomerular filtration rate at month 12 was noninferior in the everolimus groups vs the mycophenolic acid group $(54.6 \mathrm{~mL} / \mathrm{min}$ and $51.3 \mathrm{vs} 52.2 \mathrm{~mL} / \mathrm{min}$ in the everolimus $1.5 \mathrm{mg} /$ day and $3 \mathrm{mg} /$ day and mycophenolic acid groups, respectively). In this study, the use of everolimus, with progressive reduction in cyclosporine exposure of up to $60 \%$ at 1 year resulted in similar efficacy and renal function compared with standardexposure cyclosporine plus mycophenolic acid.

In a smaller study, ${ }^{34} 106$ patients were randomized to receive either high-exposure everolimus (8-12 levels) and

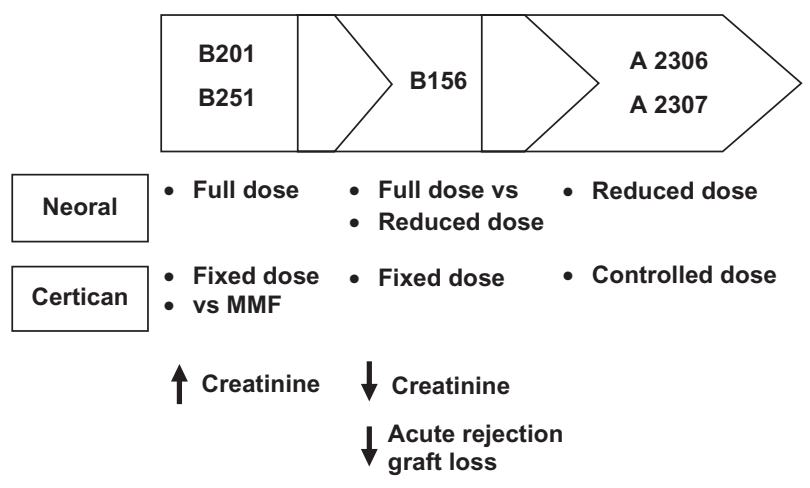

Figure 8 III) Optimizing the use of everolimus $\left(\right.$ Certican $\left.^{\circledR}\right)$ in renal transplantation. 
very low-dose cyclosporine (C2 150-250, 73\% reduction) and corticosteroids or enteric-coated mycophenolic acid $1440 \mathrm{mg}$ /day and standard-dose cyclosporine (C2 500-700) plus steroids. All patients received induction with basiliximab. The primary endpoint was estimated glomerular filtration rate by Cockcroft-Gault at 24 months. The secondary endpoint was evaluated as efficacy failure. The analysis was conducted per protocol, and all analyzed patients had drug levels in the specified range for the whole period. Patients with graft loss or who had switched to other therapies were not considered.

At 24 months, everolimus patients had a significantly higher estimated glomerular filtration rate with respect to enteric-coated mycophenolic acid patients $(77.78 \pm 31.9$ vs $54.76 \pm 18.76 \mathrm{~mL} / \mathrm{min} ; P<0.001)$. Biopsy-proven acute rejections were higher in the everolimus group, but not significantly so in the enteric-coated mycophenolic acid group (24\% vs 18\%, not statistically significant). The study conclusions were that high-exposure everolimus associated with very low cyclosporine exposure compared with enteric-coated mycophenolic acid associated with standard cyclosporine exposure was safe and effective, with a lower incidence of biopsy-proven acute rejection and a significantly higher estimated glomerular filtration rate at 2 years. These latter studies seem to have different results, mainly in terms of renal function. We should observe relevant differences between the two studies. First of all, the study dimension is in favor of A2309. Nonetheless, in this study, the analysis has been made on an intention to treat basis, and almost 30\% patients had discontinuation of their assigned therapy. More importantly, the statistical analysis was made using the last-observation-carried-forward approach, imputing missing glomerular filtration rates at 12-month analysis, with a value of zero.

Fewer studies have been done to explore the association of everolimus and tacrolimus. The most important one is US09, a prospective, 6-month, multicenter, open-label, exploratory study enrolling de novo renal transplant recipients who were randomized to receive everolimus, steroids, and basiliximab with low or standard tacrolimus exposure. ${ }^{35}$ The results were similar to those obtained with cyclosporine, and lower tacrolimus exposure was not associated with loss of efficacy compared with the standard dose. The 6-month renal function was excellent in both groups.

For a better understanding of the pharmacokinetic interrelationship between everolimus and tacrolimus, an investigator-driven, prospective, open-label, randomized Phase II pharmacokinetic study was undertaken in five
Spanish centers. ${ }^{36}$ Patients were randomly assigned to receive either tacrolimus (standard dose) and corticosteroids with everolimus $1.5 \mathrm{mg} /$ day or tacrolimus (standard dose) and corticosteroids with everolimus $3 \mathrm{mg} /$ day. Complete 12-hour pharmacokinetic curves for both drugs were done at days 4 , 14 , and 42 following transplant. The authors concluded that, in adult renal transplant recipients, everolimus significantly decreases the oral bioavailability of tacrolimus in a dosedependent manner. Everolimus doses higher than $3 \mathrm{mg} /$ day and therapeutic dose monitoring are probably needed for tacrolimus minimization strategies because, in this setting, $3 \mathrm{mg} /$ day is not enough to achieve levels more than $3 \mathrm{ng} / \mathrm{mL}$ during the first weeks.

\section{Very low calcineurin inhibitor exposure in association with everolimus}

Due to the synergistic effect between cyclosporine and everolimus documented in the aforementioned studies, a new approach using a further reduction of cyclosporine exposure and increased everolimus exposure has been evaluated in a new trial.

In the EVEREST study, ${ }^{28}$ after induction with basiliximab, patients were enrolled either to receive a very high everolimus dose (to reach $\mathrm{C} 0$ between $8-12 \mathrm{ng} / \mathrm{mL}$ ) in association with very low-dose cyclosporine (to reach C2 150-300 ng/mL) and steroids, or to receive standard-dose everolimus ( $\mathrm{C} 03-8 \mathrm{ng} / \mathrm{mL})$ in association with low-dose cyclosporine (C2 350-500 ng/mL) and steroids. The aim of EVEREST was to evaluate if higher exposure to everolimus in combination with very low exposure to cyclosporine achieves better renal function 6 months after transplantation in comparison with a standard dose. The strength of this study was that it confirmed the efficacy and safety of this new association therapy with a similar rate of acute rejection and few dropouts. The weakness of the study was the lack of compliance of the investigators in keeping cyclosporine levels as low as they should have. As a consequence, the primary endpoint was missed, and better renal function could not be detected in the very low-dose cyclosporine arm. The reduction of cyclosporine exposure throughout the study was as high as $73 \%$. Such reduction was never reached previously in studies attempting to minimize cyclosporine exposure (Figure 9).

The EVEREST study conclusions were that the combination of everolimus with very low-dose cyclosporine starting immediately after transplant is effective and well tolerated, and the noninferiority of upper everolimus/very low-dose 


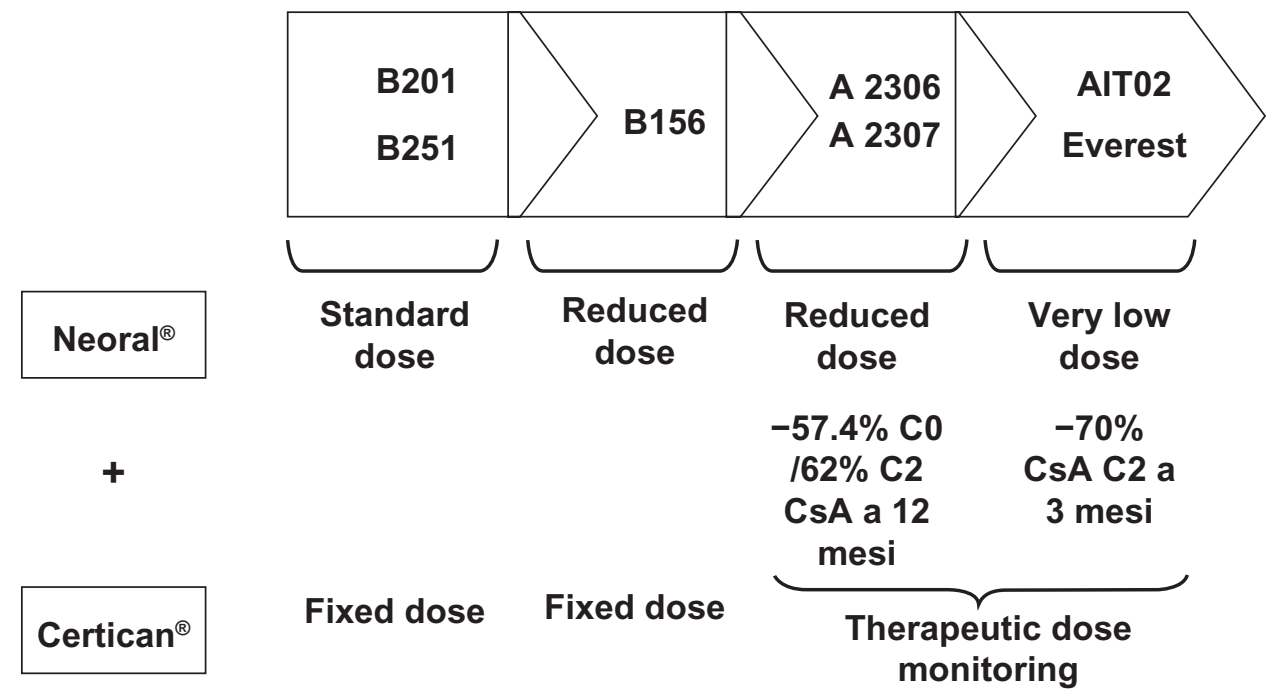

Figure 9 IV) Optimizing the use of everolimus $\left(\right.$ Certican $\left.^{\circledR}\right)$ in renal transplantation.

cyclosporine was proven in terms of biopsy proven acute rejection and therapy failures. The upper everolimus/very low-dose cyclosporine group did not have a higher incidence of adverse events than the standard everolimus group. Overall patient retention of the everolimus/cyclosporine regimen at 24 months was $71 \%$.

\section{Calcineurin inhibitor withdrawal}

The most important and recent study of calcineurin inhibitor withdrawal with everolimus has been the ZEUS study. ${ }^{29}$ The ZEUS study was a prospective, multicenter, randomized, controlled, parallel-group trial in recipients of de novo renal transplants. The purpose of the study was to assess whether treatment with everolimus in combination with enteric-coated mycophenolic sodium starting 4.5 months after kidney transplantation resulted in equal efficacy and safety but better renal function compared with a regimen consisting of enteric-coated mycophenolic sodium and cyclosporine. After initial treatment with cyclosporine, based on trough concentrations, and enteric-coated mycophenolic sodium $1440 \mathrm{mg}$ /day, corticosteroids, and basiliximab induction, 300 patients were randomly assigned at 4.5 months to undergo calcineurin inhibitor elimination and increasing everolimus trough levels $(6-10 \mathrm{ng} / \mathrm{mL})$. The primary efficacy endpoint was glomerular filtration rate at month 12 . Secondary endpoints were biopsy-proven acute rejection, graft loss, death, loss to follow-up, and drug discontinuation. At month 12 , glomerular filtration rate was significantly higher in the everolimus group, and the incidence of biopsy-proven acute rejection was similar between the groups. In conclusion, this study demonstrated that these two regimens have similar efficacy and safety, but the everolimus and enteric-coated mycophenolic sodium group had significantly improved renal function. The ZEUS regimen reflects a therapeutic approach of maintaining stable renal function without compromising efficacy and safety.

\section{Long-term safety}

Study drug discontinuation is a direct measure of safety and tolerability ${ }^{37}$ In general, drug discontinuation is linked to the occurrence of adverse events. In early studies, eg, Study 251, the incidence of suspected drug-related adverse events was comparable in all three groups $(75.6 \%, 78.4 \%$, and $73.5 \%$, respectively). Recently, in Study A2309, the incidence of adverse events leading to drug discontinuation was $36.5 \%$ for everolimus $1.5 \mathrm{mg} / \mathrm{day}, 47.1 \%$ for everolimus $3 \mathrm{mg} /$ day, and $43.6 \%$ for cyclosporine and enteric-coated mycophenolic sodium. ${ }^{33}$ In Study 251, the only significant differences in adverse events at 36 months were for anemia (mycophenolate mofetil $21.4 \%$ vs everolimus $1.5 \mathrm{mg}$ /day, $32.1 \%, P=0.02$; and everolimus $3 \mathrm{mg} / \mathrm{day}, 39.2 \%, P=0.0002)$ and peripheral edema (mycophenolate mofetil $41.8 \%$ vs everolimus $1.5 \mathrm{mg} /$ day, $52.3 \%, P=0.04$; and everolimus $3 \mathrm{mg} /$ day, $47.4 \%, P=0.31)$. These data were confirmed by Study 201, but not for anemia.

The antiproliferative effects of everolimus are not limited to the immune system. ${ }^{38}$ Indeed, the antiproliferative effect is due to blockade of the mTOR serine-threonine kinase pathway which is common to almost all cells in the body. This antiproliferative effect has beneficial effects, but is also a disadvantage of the drug (Table 5). Everolimus exhibits a protective effect against viral diseases, in particular 
Table 5 Beneficial and adverse events linked to the antiproliferative effect

\begin{tabular}{ll}
\hline Beneficial effects & Adverse effects \\
\hline Antiviral & Proteinuria \\
& Wound healing \\
Antiatherosclerotic & Lymphocele \\
Antineoplastic & Delayed graft function \\
\hline
\end{tabular}

cytomegalovirus. Table 6 shows the different incidences of cytomegalovirus infection in different studies and in different arms. As can be seen, everolimus therapy is associated with a very low incidence of cytomegalovirus in every study and in every arm using everolimus. This is an intrinsic property of the molecule, and is not due to a direct antiviral action, but to a proapoptotic action. Indeed, cytomegalovirus infection and dissemination in the host requires viability of the epithelial cells of the host that are primarily infected. Cytomegalovirus then replicates and spreads to monocytes in the peripheral blood. Infected monocytes promote cytomegalovirus migration into host organ tissues. ${ }^{39}$ The activity of everolimus against cytomegalovirus is noteworthy, because cytomegalovirus disease is associated with allograft rejection, decreased graft and patient survival, and predisposition to malignancies. ${ }^{40}$

In a randomized, prospective, controlled trial, the incidence of new malignancies was lower in patients receiving sirolimus compared with those receiving other immunosuppressive agents. ${ }^{41}$ This can be ascribed to the above mentioned activity of the drug in the mTOR kinase pathway common to all cells, including cancer cells. A peculiar effect of mTOR inhibitors, including everolimus, is blockade of angiogenesis. This is due to the prevention of vascular remodeling and interference with hypoxia inducible factors. These factors cause overexpression of hypoxia inducible factor- 1 target gene products, such as vascular endothelial growth factor. Vascular endothelial growth factor and other factors are thought to be the key drivers of tumor angiogenesis, enabling the growth and progression of cancers. Even if the short follow-up duration of the everolimus trials does not permit any conclusions regarding the magnitude of an epidemiologically significant antineoplastic effect in kidney transplantation, the efficacy of everolimus in cancers, outside the field of transplantation, has been documented in renal cell carcinoma, ${ }^{42}$ in neuroendocrine tumors, ${ }^{43}$ and in hepatocellular cancer. ${ }^{44} \mathrm{In}$ such studies, the everolimus doses to be administered were higher than those used in transplantation. Notwithstanding this, the side effects are almost similar. ${ }^{45}$

Interestingly, proliferation signal inhibitors have been shown to inhibit smooth muscle cells and proliferation of endothelial cells, thereby preventing vascular remodeling. $\mathrm{m}$-TOR inhibitors may also exert cardioprotective effects in a similar manner. Animal data suggest that $\mathrm{m}$-TOR inhibitors may restrict the pathogenesis of atherosclerosis, consistent with preliminary clinical data showing that switching from calcineurin inhibitors to everolimus can stabilize markers of arterial stiffness. Use of m-TOR inhibitors has the potential to reduce the burden of cardiovascular disease following kidney transplantation, an opportunity that merits further exploration. The use of mTOR inhibitors has been associated with delayed recovery from ischemia-reperfusion injury. This effect is more associated with sirolimus, perhaps because of the initial oral load necessary to reach steady state. ${ }^{46}$ This effect seems not to be associated with everolimus, and has not been seen in patients at risk of developing delayed graft function. ${ }^{33,47}$

Wound healing problems and lymphocele formation have also been related to the use of proliferation signal inhibitors. These effects could be related to the antiproliferative effect of these drugs on fibroblasts. Early clinical trials (B201, B251) indicated a higher lymphocele formation rate in patients receiving everolimus than in those receiving mycophenolate. Recently, the A2309 study confirmed a higher incidence of wound healing problems in patients receiving everolimus. This is an indication to avoid putting obese patients on proliferation signal inhibitors, not to use loading doses of proliferation signal inhibitors, to adjust proliferation signal inhibitor levels, and to avoid or minimize the use of steroids.

In the majority of studies, mean cholesterol and triglyceride concentrations were higher among patients receiving everolimus compared with those receiving

Table 6 Cytomegalovirus infection rate in everolimus therapy

\begin{tabular}{llllllll}
\hline Study & Ev I.5 mg & Ev 3 mg & MMF & Ev 3 mg + FD N & Ev 3 mg + RD N & Ev I.5 + TDM N & Ev 3 mg + TDM N \\
\hline $25 \mathrm{I}$ & $5.2 \%$ & $4.1 \%$ & $6.1 \%$ & & & & \\
201 & $5.7 \%$ & $8.1 \%$ & $19.9 \%$ & & $0 \%$ & & \\
B156 & & & & $1.9 \%$ & & $0.9 \%$ & $3.2 \%$ \\
A2306 & & & & & $2.6 \%$ & $2.2 \%$ \\
A2307 & & & & & & \\
\hline
\end{tabular}

Abbreviations: DN, full dose Neoral; ev, everolimus; FD N, full dose Neoral; MMF, mycophenolate mofetil; RDN, reduced dose Neoral; TDM N, Therapeutic Dose Monitoring Neoral. 
mycophenolic acid, despite a higher proportion of patients receiving lipid-lowering agents. Due to the short duration of follow-up, it is difficult to assess the impact of these changes in dyslipidemia on cardiovascular disease.

Proteinuria has been described in patients switched from calcineurin inhibitors to everolimus, and also in renal transplant patients treated de novo with everolimus. In the B251 study, values of $1 \mathrm{~g} /$ day were observed in $11 \%$ vs $2 \%$ in the everolimus and mycophenolic acid groups, respectively. Proteinuria was detected in $<5 \%$ of patients in the A2306 and A2307 studies. In the A2309 study, the rate of proteinuria in the everolimus group was twice that in the enteric-coated mycophenolic acid group. Proteinuria is important because it is a hallmark of progressive deterioration of renal function. However, the mechanism of proliferation signal inhibitorinduced proteinuria continues to be debated. ${ }^{48}$

In a study comparing renal function and characteristics of proteinuria in sirolimus-treated vs cyclosporine-treated patients, kidney function was similar in both groups, but levels of markers associated with glomerular damage (ie, albumin and transferrin), and those associated with tubular damage (alpha1-microglobulin and retinol-binding protein) were higher at day 7 in patients on sirolimus therapy, with similar findings at day $90 .{ }^{49}$

A recent proteomics analysis with protocol biopsies ${ }^{50}$ ascribed proteinuria to the antiproliferative and proapoptotic effects of everolimus. Proteinuria was mainly of tubular origin, and associated with increased apoptosis of tubular cells and podocytes. Proteinuria appeared in the early period after transplantation and disappeared over the longer term. In this study, proteinuria was not associated with deterioration of renal function.

In another study comparing high-dose everolimus and very low-dose cyclosporine with enteric-coated mycophenolate sodium and standard-dose cyclosporine, ${ }^{34}$ everolimus patients had higher proteinuria immediately after transplantation, but this disappeared with time. One year after transplantation, the incidence of proteinuria was low and similar in both groups. Renal function was significantly better in everolimus patients.

\section{Endothelium, atherosclerosis, and heart transplantation}

As already mentioned, the antiproliferative effects of everolimus are not limited to the immune system. ${ }^{38}$ Proliferation signal inhibitors have been shown to inhibit proliferation of smooth muscle cells and endothelial cells, thereby preventing vascular remodeling. This property may represent an additional benefit of everolimus, because these proliferative processes are implicated in the development of cardiac allograft vasculopathy in cardiac allograft recipients. ${ }^{51,52}$

Repetitive cycles of cytokine release, upregulation of growth factors, and smooth muscle cell proliferation may cause diffuse vascular luminal narrowing and intimal thickening that can be reversed by everolimus. ${ }^{53}$ Cardiac allograft vasculopathy after heart transplantation is an accelerated form of coronary disease characterized by diffuse and progressive thickening of the intima along the entire length of affected intramyocardial arteries. There are various immunologic and nonimmunologic factors underlying cardiac allograft vasculopathy that act on the wall of the grafted coronary vessels, damaging the endothelium, and triggering release of proliferative substances. These processes cause growth of the intimal layer by proliferation and migration of smooth muscle cells, and deposition of a connective tissue matrix. ${ }^{54}$ In general terms, it has been established that the prevalence of cardiac allograft vasculopathy at 5 years after transplantation is almost $50 \%$ and reaches $100 \%$ at 10 years.

The antiatherosclerotic activity of everolimus is mostly important in heart transplantation where cardiac allograft vasculopathy is the main cause of chronic rejection. This effect is linked to the antiproliferative effect exerted on vascular smooth muscle cells and endothelial cells, so preventing vascular remodeling. Moreover, even if everolimus causes blood lipid increase, the drug has a protective effect on atherosclerosis. Such an effect could be linked to an antiproliferative p27 Kip-dependent mechanism, involving abrogation of the upregulation of MCP-1 mRNA expression, which promotes monocyte chemoattraction, "stabilization" of vessel wall architecture via increased transforming growth factor- $\beta$, suppression of low-density lipoprotein and very low-density lipoprotein receptors and CD36 gene expression, and increased cholesterol efflux from human mesangial cells. The beneficial effects of everolimus in atherosclerotic disease were firstly documented in the treatment of vascular lesions using an everolimus-eluting stent. Newer generation stents also seem to be highly effective.$^{55}$ Obviously, in this setting, the effects on the endothelium are greater because of the high local drug concentrations.

RAD B $253^{56}$ was a prospective, multicenter, double-blind study in which 634 patients were randomized after heart transplantation into three arms to receive either everolimus $1.5 \mathrm{mg} /$ day or $3 \mathrm{mg} /$ day or azathioprine, in combination with cyclosporine and steroids (Figure 10). After 12 months, the mean increase in coronary media-intima thickness among azathioprine-treated patients was more than double that observed in both the everolimus arms, and the incidence of 
To compare the efficacy and safety of each of two oral doses of $\operatorname{RAD}(1.5 \mathrm{mg} / \mathrm{day}$ and $3.0 \mathrm{mg} /$ day with azathioprine) in de novo heart transplant recipients

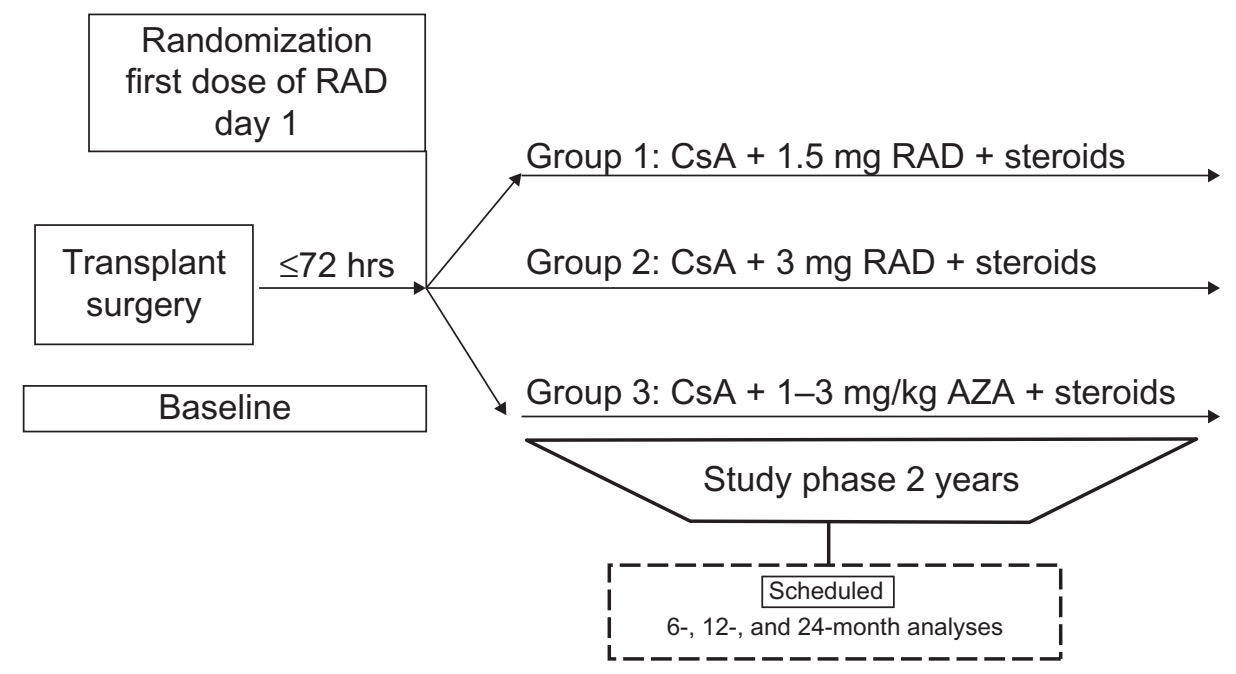

Figure 10 Overall study design and objectives.

vasculopathy, evaluated by intravascular ultrasonography, was also significantly higher in this group, at $52.8 \%$ vs $35.7 \%$ and $30.4 \%$. The results were confirmed at 24 months. ${ }^{57}$

The RAD B253 data at 4 years showed that significantly fewer patients on everolimus had a major cardiovascular event related to cardiac allograft vasculopathy compared with patients treated with azathioprine. In addition, according to an economic analysis, everolimus is associated with a decrease of $57.2 \%$ in the average cost of treatment for such events. ${ }^{54}$

In another large multicenter study of everolimus in heart transplantation (RAD 2411) ${ }^{58}$ everolimus (trough level 3-8 $\mathrm{ng} / \mathrm{mL}$ ) with reduced cyclosporine was compared with mycophenolate mofetil $3 \mathrm{~g} /$ day plus standard cyclosporine. Overall, 176 patients were randomized into a 12-month, multicenter, open-label study. All efficacy endpoints were noninferior for everolimus vs mycophenolate mofetil. The 12-month incidence of biopsy-proven acute rejection grade $\geq 3 \mathrm{~A}$ was 21 of $92(22.8 \%)$ with everolimus and 25 of 84 (29.8\%) with mycophenolate mofetil. Adverse events were consistent with class effects, including less frequent cytomegalovirus infection with everolimus (four [4.4\%]) vs mycophenolate mofetil (14 [16.9\%], $P=0.01)$. In summary, everolimus was effective in preventing both acute and chronic rejection in heart transplantation in comparison with antiproliferative agents, such as azathioprine and mycophenolate mofetil. The drug discontinuation rate was similar for low-dose everolimus and azathioprine. As in kidney transplantation, an antiviral effect was documented in both studies. Wound healing events were higher in everolimus patients. Serum lipid levels were also higher in everolimus patients.

\section{Conclusion}

The efficacy and safety of everolimus in renal transplantation have been confirmed by several studies. The possibility of cyclosporine dose reduction became evident since the early studies when everolimus and cyclosporine were administered as fixed doses, and several trials documented the efficacy and safety of everolimus when given with a low cyclosporine dose. Given the potential nephrotoxicity as a consequence of interference by everolimus with calcineurin inhibitors, the best therapeutic regimen using these drugs involves therapeutic dose monitoring of both agents. Recently, the association of very high everolimus exposure with very low cyclosporine exposure has been shown to be a promising therapeutic regimen in renal transplantation. Everolimus has an antiproliferative effect not only on the immune system, but also on other cells. This antiproliferative effect gives the drug relevant antiviral activity. Almost all the trials with everolimus documented a significantly lower incidence of cytomegalovirus infection and disease in the everolimus arms with respect to mycophenolic acid. The antiproliferative effect on vascular smooth cells and endothelial cells avoids vascular remodeling after transplantation. This effect has been the basis of everolimus use in heart transplantation where the vascular remodeling is the main 
hallmark of chronic rejection. The antiproliferative effect on fibroblasts is also the basis of the main drawbacks of the drug, ie, lymphoceles, delayed wound healing, and proteinuria. To avoid such problems, careful use of the drug in the early posttransplant period is recommended.

\section{Disclosure}

The authors report no conflicts of interest in this work.

\section{References}

1. Meier-Kriesche HU, Schold HD, Srinivas TR, Kaplan B. Lack of improvement in renal allograft survival despite a marked decrease in acute rejection rates over the most recent era. Am J Transplant. 2004;4: 378-383.

2. Gjertson DW. Survival trends in long-term first cadaver-donor kidney transplants. Clin Transpl. 1991:225-235.

3. Meier-Kriesche HU, Schold JS, Kaplan B. Long term renal allograft survival: Have we made a significant progress or is it time to rethink our analytic and therapeutic strategies? Am J Transplant. 2004;4: 1289-1295.

4. Nankivell BJ, Burrows RJ, Fung CL, et al. The natural history of chronic allograft nephropathy. N Engl J Med. 2003;349:2326-2333.

5. Abramowicz D, Manas D, Lao M, et al. Cyclosporine withdrawal from a mycophenolate mofetil-containing immunosuppressive regimen in stable kidney transplant recipients: A randomized, controlled study. Transplantation. 2002;74:1725-1734.

6. Ekberg H, Grinyò J, Nashan B, et al. Cyclosporine sparing with mycophenolate mofetil, daclizumab and corticosteroids in renal allograft recipients: The Caesar study. Am J Transplant. 2007;7: 560-570.

7. Hudes G, Carducci M, Tomczak P, et al. Temsirolimus, interferon alfa, or both for advanced renal cell carcinoma. N Engl J Med. 2007; 356:2271-2281.

8. Wullschleger S, Loewith R, Hall MN. mTOR signalling in growth and metabolism. Cell. 2006;124:471-484.

9. Augustine JJ, Bodziak KA, Hricik DE. Use of sirolimus in solid organ transplantation. Drugs. 2007;67:369-391.

10. Kirchner GI, Meier-Wiedenbach I, Manns MP. Clinical pharmacokinetics of everolimus. Clin Pharmacokinet. 2004;43:83-95.

11. MacDonald AS. Use of mTOR inhibitors in human organ transplantation. Exper Rev Clin Immunol. 2007;3:423-436.

12. Kovarik JM, Kahan BD, Kaplan B, et al. Longitudinal assessment of everolimus in de novo renal transplant recipients over the first post-transplant year: Pharmacokinetics, exposure-response relationships, and influence on cyclosporine. Clin Pharmacol Ther. 2001;69: 48-56.

13. Kovarik JM, Kaplan B, Tedesco Silva H, et al. Pharmacokinetics of an everolimus-cyclosporine regimen over the first 6 months after kidney transplantation. Am J Transplant. 2003;3:606-613.

14. Kovarik JM, Eisen H, Dorent R, et al. Everolimus in de novo cardiac transplantation: Pharmacokinetics, therapeutic range, and influence on cyclosporine exposure. $J$ Heart Lung Transplant. 2003;22: $1117-1125$.

15. Neumayer HH, Paradis K, Korn A, et al. Entry-into-human study with the novel immunosuppressant SDZ RAD in stable renal transplant recipients. Br J Clin Pharmacol. 1999;48:694-703.

16. Budde K, Neumayer HH, Lehne G, et al. Tolerability and steadystate pharmacokinetics of everolimus in maintenance renal transplant patients. Nephrol Dial Transplant. 2004;19:2606-2614.

17. Kovarik JM, Hartmann S, Figuiredo J, et al. Effect of food on everolimus absorption: Quantification in healthy subjects and a confirmatory screening in patients with renal transplants. Pharmacotherapy. 2002;22: $154-159$.
18. Serkova N, Hausen B, Berry GJ, et al. Tissue distribution and clinical monitoring of the novel macrolide SDZ-RAD and its metabolites in monkey lung transplant recipients: Interaction with cyclosporine. J Pharmacol Exp Ther. 2000;294:323-332.

19. Nashan B. Early clinical experience with a novel rapamycin derivative. Ther Drug Monit. 2002;24:53-58.

20. Schuurman HJ, Cottens S, Fuchs S, et al. SDZ RAD: A new rapamycin derivative, synergy with cyclosporine. Transplantation. 1997;64: 32-35.

21. Schuler W, Sedrani R, Cottens S, et al. SDZ RAD: A new rapamycin derivative, pharmacological properties in vitro and in vivo. Transplantation. 1997;64:36-42.

22. Hausen B, Gummert J, Berry GJ, et al. Prevention of acute allograft rejection in nonhuman primate lung transplant recipients: Induction with chimeric anti-interleukin-2 receptor monoclonal antibody improves the tolerability and potentiates the immunosuppressive activity of a regimen using low doses of both microemulsion cyclosporine and 40-O-(2-hydroxyethyl)-rapamycin. Transplantation. 2000;69:76-86.

23. Nashan B, Curtis J, Ponticelli C, Mourad G, Jaffe J, Haas T. 156 Study Group. Everolimus and reduced-exposure cyclosporine in de novo renaltransplant recipients: A three-year phase II, randomized, multicenter, open label study. Transplantation. 2004;78:1332-1340.

24. Vitko S, Margreiter R, Weimar W, et al. Everolimus (Certican) 12-month safety and efficacy versus mycophenolate mofetil in de novo renal transplant recipients. Transplantation. 2004;78:1532-1540.

25. Vitko S, Margreiter R, Weimar W, et al. Three-year efficacy and safety results from a study of everolimus versus mycophenolate mofetil in de novo renal transplant patients. Am J Transplant. 2005;5:2521-2530.

26. Lorber MI, Mulgaonkar S, Butt KM, et al. Everolimus versus mycophenolate mofetil in the prevention of rejection in de novo renal transplant recipients: a 3-year randomized, multicenter, phase III study. Transplantation. 2005;80:244-252.

27. Vitko S, Tedesco H, Eris J, et al. Everolimus with optimized cyclosporine dosing in renal transplant recipients: 6-month safety and efficacy results of two randomized studies. Am J Transplant. 2004;4:626-635.

28. Salvadori M, Scolari MP, Bertoni E, et al. Everolimus with very lowexposure cyclosporine $\mathrm{A}$ in de novo kidney transplantation: A multicenter, randomized, controlled trial. Transplantation. 2009;88:1194-1202.

29. Budde K, Becker T, Arns W, et al. Everolimus-based, calcineurininhibitor-free regimen in recipients of de-novo kidney transplants: An open-label, randomised, controlled trial. Lancet. 2011;377:837-847.

30. Lorber MI, Ponticelli C, Whelchel J, et al. Therapeutic drug monitoring for everolimus in kidney transplantation using 12-month exposure, efficacy, and safety data. Clin Transplant. 2005;19:145-152.

31. Sanchez-Fructuoso AI. Everolimus: An update on the mechanism of action, pharmacokinetics and recent clinical trials. Expert Opin Drug Metab Toxicol. 2008; $4 ; 807-818$.

32. Pascual J. The use of everolimus in renal-transplant patients. Int $J$ Nephrol Renovasc Dis. 2009;2:9-21.

33. Tedesco Silva H Jr, Cibrik D, Johnston T, et al. Everolimus plus reducedexposure CsA versus mycophenolic acid plus standard-exposure CsA in renal transplant recipients. Am J Transplant. 2010;10:1-13.

34. Bertoni E, Larti A, Rosso G, Zanazzi M, Di Maria L, Salvadori M. Good outcomes with cyclosporine very low exposure with everolimus high exposure in renal transplant patients. J Nephrol. January 14, 2011. [Epub ahead of print].

35. Chan L, Greenstein S, Hardy MA, et al. Multicenter, randomized study of the use of everolimus with tacrolimus after renal transplantation demonstrates its effectiveness. Transplantation. 2008;85:821-826.

36. Pascual J, del Castillo D, Cabello M, et al. Interaction between everolimus and tacrolimus in renal transplant recipients: A pharmacokinetic controlled trial. Transplantation. 2010;89:994-1000.

37. Tedesco-Silva H Jr, Rosso Felipe C, de Sandes Freitas TV, Pontello Cristeli M, Araùjo Rodrigues C, Medina Pestana JO. Impact of everolimus: Update on immunosuppressive therapy strategies and patient outcomes after renal transplantation. Transplant Research and Risk Management. 2011;3:9-29. 
38. Schuler W, Sedrani R, Cottens S, et al. SDV RAD, a new rapamycin derivative: Pharmacological properties in vitro and in vivo. Transplantation. 1997;64:36-42.

39. Smith MS, Bentz GL, Smith PM, Bivins ER, Yurochko AD. HCMV activates $\mathrm{PI}(3) \mathrm{K}$ in monocytes and promotes monocyte motility and trans-endothelial migration in a $\mathrm{PI}(3) \mathrm{K}$-dependent manner. J Leukoc Biol. 2004;76:65-76.

40. Fishman JA, Emery V, Freeman R, et al. Cytomegalovirus in transplantation - challenging the status quo. Clin Transplant. 2007;21:149-158.

41. Campistol JM, Eris J, Oberbauer R, et al. Sirolimus therapy after early cyclosporine withdrawal reduces the risk for cancer in adult renal transplantation. J Am Soc Nephrol. 2006;17:581-589.

42. Motzer RJ, Escudier B, Oudard S, et al. Efficacy of everolimus in advanced renal cell carcinoma: A double-blind, randomized, placebocontrolled phase III trial. Lancet. 2008;372:449-456.

43. Yau JC, Phan AT, Chang DZ, et al. Efficacy of RAD001 (everolimus) and octreotide LAR in advanced low and intermediate grade neuroendocrine tumors: Results of a phase II study. J Clin Oncol. 2008;26: 4311-4318

44. Treiber G. mTOR inhibitors for hepatocellular cancer: A forwardmoving target. Expert Rev Anticancer Ther. 2009;9:246-261.

45. Gabardi S, Baroletti S. Everolimus: A proliferation signal inhibitor with clinical applications in organ transplantation, oncology and cardiology. Pharmacotherapy. 2010;30:1044-1056.

46. Stallone G, Di Paolo S, Schena A, et al. Addition of sirolimus to cyclosporine delays the recovery from delayed graft function but does not affect 1-year graft function. J Am Soc Nephrol. 2004;15:228-233.

47. Albano L, Berthoux F, Moal MC, et al. Incidence of delayed graft function and wound healing complications after deceased-donor kidney transplantation is not affected by de novo everolimus. Transplantation. 2009;88:69-76.

48. Letavernier E, Legendre C. mTOR inhibitors-induced proteinuria: Mechanisms significance and management. Transplant Rev. 2008;22: 125-130.
49. Franz S, Tregeniter A, Hopfer H, Mihatsch M, Dickermann N. Tubular toxicity in sirolimus- and cyclosporine-based transplant immunosuppression strategies: An ancillary study from a randomized controlled trial. Am J Kidney Dis. 2010;55:335-343.

50. Bertoni E, Bruschi M, Candiano G, et al. Post-transplant proteinuria associated with everolimus. Transplant Proc. 2009;41:216-217.

51. Cao W, Mohacsi P, Shorthouse R, Pratt R, Morris RE. Effects of rapamycin on growth-factor stimulated vascular smooth muscle cell DNA synthesis. Inhibition of basic fibroblast growth factor and plateletderived growth factor action and antagonism of rapamycin by FK506. Transplantation. 1995;59:390-395.

52. Schuurman HJ, Pally C, Weckbecker G, Schuler W, Bruns C. SDZ RAD inhibits cold-ischemia induced vascular remodeling. Transplant Proc. 1999;31:390-395

53. Neumayer HH. Introducing everolimus (Certican. in organ transplantation: An overview of preclinical and early clinical developments. Transplantation. 2005;79(9 Suppl):S72-S75.

54. Delgado JF, Manito N, Segovia J, et al. The use of proliferation signal inhibitors in the prevention and treatment of allograft vasculopathy in heart transplantation. Transplant Rev (Orlando). 2009;23:69-79.

55. Shimohama T, Ako J, Yamasaki M, et al. SPIRIT III JAPAN versus SPIRIT III USA: A comparative intravascular ultrasound analysis of the everolimus-eluting stent. Am J Cardiol. 2010;106:13-17.

56. Eisen HJ, Murat Tuzcu E, Dorent R, et al. Everolimus for the prevention of allograft rejection and vasculopathy in cardiac-transplant recipients. N Engl J Med. 2003;349:847-858.

57. Vigano M, Tuzcu M, Benza R, et al. Prevention of acute rejection and allograft vasculopathy by everolimus in cardiac transplant recipients: A 24-month analysis. J Heart Lung Transplant. 2007;26:584-592.

58. Lehmkuhl HB, Arizon J, Viganò M, et al. Everolimus with reduced cyclosporine versus MMF with standard cyclosporine in de novo heart transplant recipients. Transplantation. 2009;88:115-122.
Transplant Research and Risk Management

\section{Publish your work in this journal}

Transplant Research and Risk Management is an international, peerreviewed open access journal focusing on all aspects of transplantation and risk management to achieve optimal outcomes in the recipient improving survival and quality of life. The journal welcomes submitted papers covering original research, basic science, clinical studies,

\section{Dovepress}

reviews \& evaluations, guidelines, expert opinion and commentary, case reports and extended reports. The manuscript management system is completely online and includes a very quick and fair peer-review system, which is all easy to use. Visit http://www.dovepress.com/ testimonials.php to read real quotes from published authors. 